\title{
CORRECTING EFFECT OF AQUEOUS EXTRACT FROM DUCKWEED LEMNA MINOR FROND ON MORPHOLOGICAL STATE OF THYROID GLAND IN RATS WITH HYPOTHYROIDISM
}

\author{
Alevtyna Kononenko \\ Department of Physiology and Human Anatomy \\ National University of Pharmacy \\ 53 Pushkinskaya str., Kharkov, Ukraine 61002 \\ alevtina_kononen@mail.ru \\ Vera Kravchenko \\ Department of Physiology and Human Anatomy \\ National University of Pharmacy \\ 53 Pushkinskaya str., Kharkov, Ukraine 61002 \\ krav4enko_vn@mail.ru
}

\begin{abstract}
The present work studied the effect of aqueous extract from duckweed Lemna minor frond on morphological state of the thyroid gland in the experimental hypothyroidism. Healthy albino rats weighing between $120 \mathrm{~g}$ and $150 \mathrm{~g}$ were used. The animalswere randomly allotted into four groups, each containing ten rats respectively. Three of the groups (II, III and IV) induced with hypothyroidism by $1 \%$ solution of sodium perchlorate with drinking water for 20 days. Control (vehicle) rats were given normal saline. After 20 days hypothyroid groups (III and IV) of rats treated with aqueous extract from duckweed Lemna minor frond at a dose $0.5 \mathrm{ml} / 100 \mathrm{~g}$ of body weight and with Iodomarin 200 (reference drug) at a dose $12 \mu \mathrm{g} / \mathrm{kg}$ daily orally for 21 days. Results obtained from the study showed that the introduction of sodium perchlorate leads to morphological and functional changes in the structure of the thyroid gland in rats, accompanied by sings of hyperplastic tissue proliferation and corresponds with hypofunctional state. It was established that introduction of aqueous extract from duckweed Lemna minor frond has a positive effect on the restructuring of the thyroid gland in rats with hypothyroidism, increasing its functional activity. There is a decrease of proliferative processes by extrafollicular epithelium and thyrocytes in the follicles. The outer diameter of follicles decreased by $7.65 \%$ ( $>>0.05)$, the height and size of thyrocytes in the wall of the follicle were significantly decreased by $58.16 \%$ and $1841 \%$, respectively, compared to untreated hypothyroid group. The obtained results have practical significance for the development of drugs with thyroid-stimulating action for preventing or delaying the development of hypothyroidism and its complications.
\end{abstract}

Keywords: aqueous extract, Lemna minor frond, experimental hypothyroidism, sodium perchlorate, morphology.

\section{Introduction}

Hypothyroidism is one of the most common dysfunction of the thyroid gland, accompanied by inhibition of many functions of organs and systems and lead to restructuring thyroid [1-5]. According to some epidemiological studies in some populations, the prevalence of hypothyroidism reaches $10-12 \%[1,6-8]$.

For the treatment of hypothyroid states of thyroid gland the replacement therapy is mainly used - thyroid hormones or therapy aimed at restoring the deficiency of iodine [9-11]. Today, according to the various estimates of significant share of the European and world pharmaceutical marketoccupied by herbal products, this share is approximately $30-50 \%[2,10]$. Arsenal of thyroid-stimulating drugs in Ukraine is characterized by uniformity of dosage forms, the predominance of imported producers, and the lack of herbal drugs [12, 13]. Therefore, there is a need to develop pharmaceutical drugswith thyroid-stimulating effect based on medicinal plants.

One of the herbs used in traditional and folk medicine to treat and prevent hypothyroidism is Lemna minor. The results of phytochemical research showed the presence of iodine and 14 elements 
(calcium, potassium, silicon, sodium, etc.) in duckweed Lemna minor frond. There were identified 32 biologically active substances of different chemical groups (phytosterols, saturated hydrocarbons, aldehydes and ketones, amino acids, fatty acids, etc.) $[14,15]$.

The aim of our research was to prove the effect of aqueous extract from duckweed Lemna minor frond on morphological state of the thyroid gland at experimental hypothyroidism [16].

\section{Materials and Methods}

Aqueous extract from duckweed Lemna minor frond obtained at the Department of Quality, Standardization and Certification of drugs (National University of Pharmacy) and standardized in accordance with the requirements of the State Pharmacopoeia of Ukrainian and European Pharmacopoeia [12]. (Iodomarin 200 (Berlin-Chemie AG/Menarini Group, Germany), sodium perchlorate and other chemicals obtained commercially.

\section{1. Experimental Animals}

Fortyalbinomale rats weighing between 120 to $150 \mathrm{~g}$ obtained and housed in the Central Scientific Research Laboratory, National University of Pharmacy, Ukraine. The normal standard rat chow and tap water provided ad libitum during the experiment. Animals were stabilized to acclimatize to animal house environment for one week before commencement of the experiment. The study protocol was approved by Bioethics Commission of the National University of Pharmacyand the "General ethical animal experimentation" (Kyiv, 2001), consistent with the provisions of the European Convention for the Protection of Vertebrate Animals used for Experimental and Other Scientific Purposes (Strasbourg, 1986).

\section{2. Experimental procedures}

\section{2. 1. Induction of Hypothyroidism}

Experimental hypothyroidism induced by sodium perchlorate in distilled drinking water (1 g per liter) for 20 days. Control (vehicle) ratsreceived equal volume of drinking water [17]. Twenty days after induction of hypothyroidism treatment of animals was starting.

\section{2. 2. Experimental Design}

Normal healthy rats used as normal control and hypothyroidism-induced rats were randomly allotted into four groups $(\mathrm{n}=10)$ :

Group 1: Normal untreated rats were given the normal saline $0.5 \mathrm{ml} / 100 \mathrm{~g}$ of body weight daily orally for 21 days.

Group 2: Hypothyroid untreated rats were given the normal saline $0.5 \mathrm{ml} / 100 \mathrm{~g}$ of body weight daily orally for 21 days.

Group 3: Hypothyroid rats were treated with aqueous extract from duckweed Lemna minorfrond $0.5 \mathrm{ml} / 100 \mathrm{~g}$ of body weight daily orally for 21 days.

Group 4: Hypothyroid rats were treated with Iodomarin $20012 \mu \mathrm{g} / \mathrm{kg}$ daily orally for 21 days.

\section{2. 3. Histological analysis}

After the experiment, animals were sacrificed by immediate decapitation and the thyroid gland removed. The lobes of thyroid glands fixed in $10 \%$ formalin solution, desiccated in alcohols with increasing concentration and embedded in paraffin-celloidine. Sections 5-6 microns thick stained with hematoxylin and eosin [18].Algorithms of histological description according to O. K. Khmelnytsky were used for pathomorphological analysis of thyroid gland. To unify histopathological studies and assay changesthe quantitative analysis (height of follicular epithelium and follicular outer diameter, number of thyrocytes in the follicular wall) of glandular tissuewas conducted. Height of follicular epithelium and follicular outer diameter $(\mu \mathrm{m})$ was measured using Toupcam Granum program. Microphotography of images was carried out using digital video camera Granum DSM 310. Photos was processed on a computer Pentium 2,4 GHz using ToupView. 


\section{3. Statistical Analysis}

All data expressed as Mean \pm SEM were entered and analyzed using «Statistica 6.0» statistical package with multiple comparisons. The Newman-Keylsatest was used to determine difference between the groups. Values of $\mathrm{P}<0.05$ were considered as statistically significant $[19,20]$.

\section{Results and discussion}

The results of the present study supply morphological and quantitative data about structure of thyroid gland in normal rats and about how its changes after sodium perchlorate induced hypothyroidism and treatment with aqueous extract from duckweed Lemna minor frond and Iodomarin 200. Thus, thyroid gland of control rats has typical follicular structure. Sections of tissue were separated from each other by thin connective septa. Thyroid follicles have various sizes, mostly round or slightly oval shape, with clear contours. The follicles on the periphery are larger than central ones. Intracellular space of follicles is filled with moderate density, uniform oxyphilic colloid. Typically, colloid fill the entire cavity of the follicle, sometimes was a little "cracked" or behind the walls of the follicles. Thyroid epithelium lined wall folliclesis mostly cubic shape, in large follicles - moderately flattened. Follicular thyrocytesis placed on the basement membrane in one row. The nuclei of cells are thick, round, centrally located. Extrafollicular epithelium looks as the islands and it is located between follicles. Perifollicular capillary net has normal blood supply (Fig. 1).

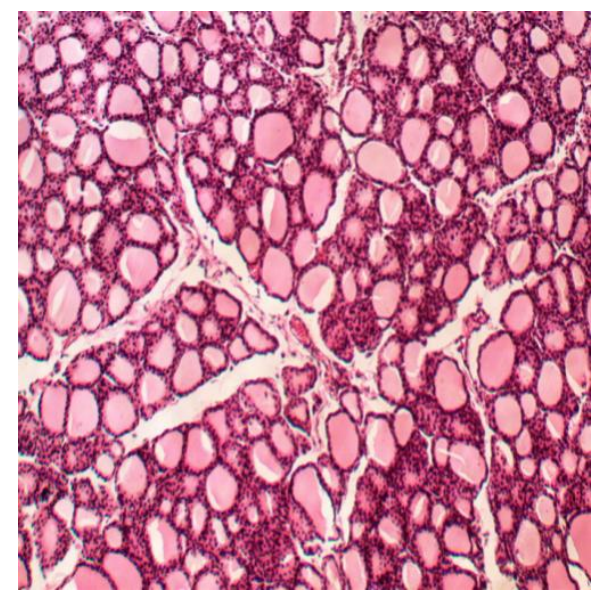

Fig. 1. Thyroid gland of control rats: normal follicular structure of glandular tissue $(\times 100)$; thyrocytes in the wall of the follicle have cubic shape, located in one row; colloid fills the entire cavity, densely. Hematoxylin-eosin

The described morphological structure of thyroid gland corresponds to the normal, viable, moderately active tissue that is confirmed by morphometric parameters (Table 1).

The data demonstrated that after 20 days introduction of sodium perchlorate with drinking water the distinct changes in the structure of the thyroid gland could be found. Thesechanges have diffuse character and hyperplastic processes observed in all rats. Most animals $(67 \%)$ follicles in different areas were monomorphicand densely adjacent to each other. Colloid in the follicular lumen is absent. Thyrocytes increased in sizewith shaded cell boundaries. The lumen of follicles is curved, reduced or absent. The nuclei of many thyrocytes have atypical shape, the hypochromic one. The cytoplasm of the vast number of cells is vacuolated. In the walls of many follicles are seen the varying degrees of forming Sandersoncushions. Extrafollicul are pit helium has sings of proliferation, often with the formation of small and micro-follicles (Fig. 2, Fig. 3, $\boldsymbol{a}, \boldsymbol{b}$ ).

The remaining animals restructuring process and hyperplasia also has a diffuse character, but was marked by a certain variability in size and shape follicles (Fig. 4). 


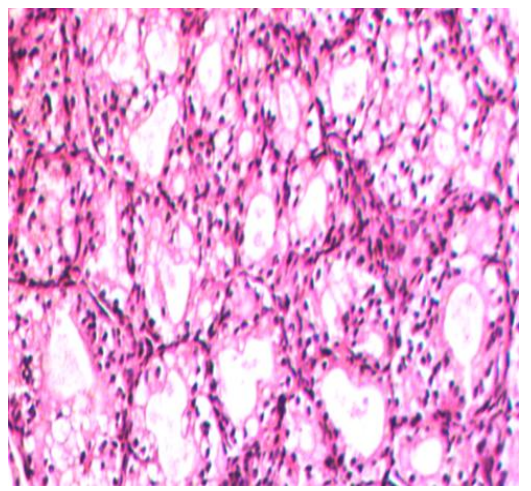

Fig. 2. The thyroid gland of rats after administration of sodium perchlorate: monomorphic follicles; dystrophy, multi rowed follicular thyrocytes, the absence of colloid in the lumen of the follicles $(\times 200)$. Hematoxylin-eosin

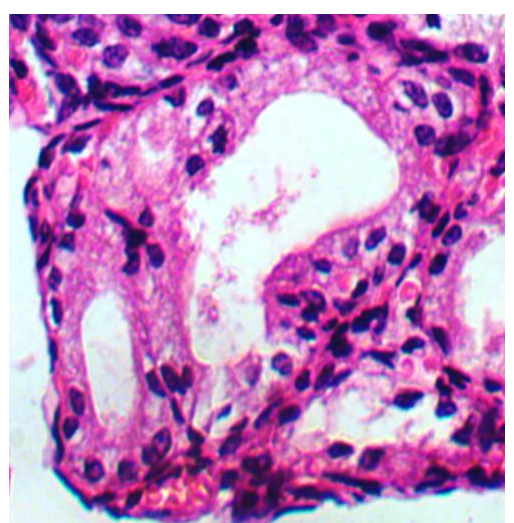

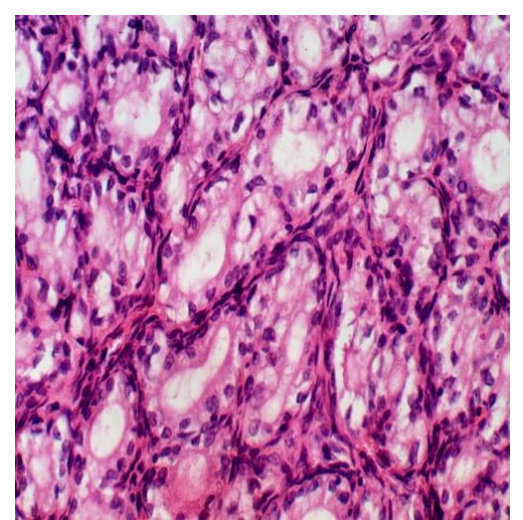

$b$

Fig. 3. The thyroid gland of rats after administration of sodium perchlorate, $a$-Sanderson cushion was formed in the wall of the follicle, mitosis of thyrocyte's nuclei $(\times 400)$; $b$ - moderate focal sclerosis $(\times 200)$. Hematoxylin-eosin

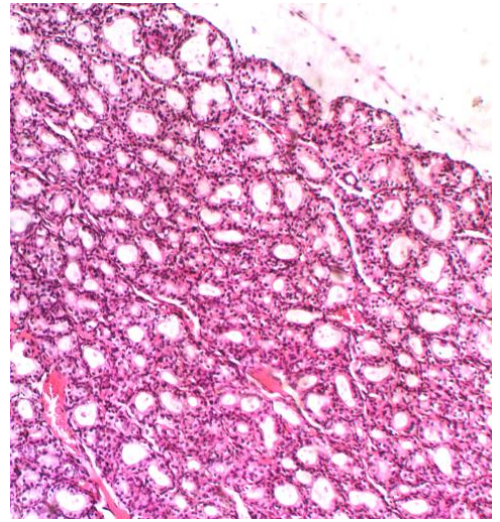

$a$

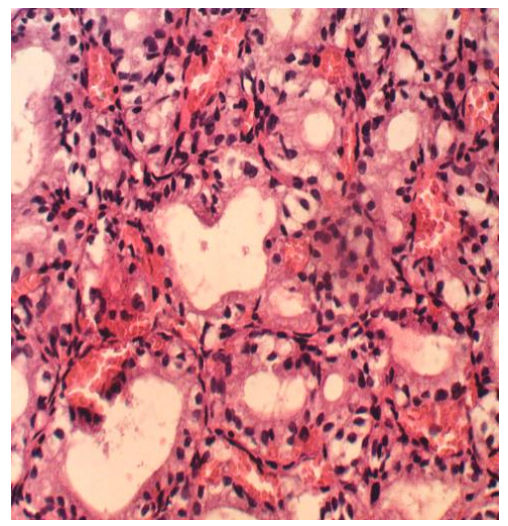

$b$

Fig. 4. Thyroid gland of rats after administration of sodium perchlorate: $a$ - some moderate variability in size and shape of follicles $(\times 100)$;

$b$ - lobular capillary hyperemia of perifollicular wall $(\times 200)$. Hematoxylin-eosin

Visual changes in the state of follicles correlated with changes in their morphometric characteristics. The average outside diameter of follicles increased by $22.16 \%(\mathrm{P}<0.05)$, thyrocytes height increased in 2.13 times $(\mathrm{P}<0.05)$, and number of thyrocytes in the wall of the follicle became more in 1.72 times $(\mathrm{P}<0.05)$ (Table 1). 
Thus, the long-term introduction of sodium perchlorate in rats resulted in significant morphological and morphometric changes of the thyroid gland of animals that correspond to the hypothyroid state with an evident goitriferous effect.

Table 1

Morphometric parameters characterizing the functional state of the thyroid gland of rats, $\mu \mathrm{m}$

\begin{tabular}{cccc}
\hline Group & $\begin{array}{c}\text { The outer diameter of } \\
\text { the follicle }\end{array}$ & $\begin{array}{c}\text { Parameters } \\
\text { Thyrocyte height }\end{array}$ & $\begin{array}{c}\text { Number of thyrocytes in } \\
\text { the wall of the follicle }\end{array}$ \\
\hline Control & $37,33 \pm 1,74$ & $5,51 \pm 0,25$ & $9,06 \pm 0,26$ \\
Hypothyroid & $47,96 \pm 1,87^{*}$ & $11,72 \pm 0,10^{*}$ & $15,56 \pm 0,80^{*}$ \\
Treated with AEDF & $44,56 \pm 2,07^{*}$ & $7,41 \pm 0,73 * * *$ & $13,14 \pm 0,73 * * *$ \\
Treated with Iodomarin & $44,91 \pm 1,75^{*}$ & $8,86 \pm 0,49 * / * *$ & $13,62 \pm 0,53^{*} / * *$
\end{tabular}

Note: AEDF - aqueous extract from duckweed Lemna minor frond. Values are mean $\pm S E M, n=10 . *-P<0.05$ versus control group; **-P<0.05 versus hypothyroid group

Structural organization of the thyroid gland of $50 \%$ of the animals treated with aqueous extract from duckweed Lemna minor frond showed its significant functional activity. Follicles, thyrocytes, colloid, extra follicular epithelium by morphological characteristics reaching the control group (Fig. 5, $\boldsymbol{c}, \boldsymbol{d}$ ). Morphometric parameters characterizing the functional state of the thyroid gland, in the whole group decreased, the outer diameter of follicles by $7.65 \%(\mathrm{P}>0.05)$, but the height and size of thyrocytes in the wall of the follicle significantly decreased by $58.16 \%(\mathrm{P}<0.05)$ and $1841 \%(\mathrm{P}<0.05)$ (Table 1). The rest $50 \%$ of the rats retained signs of hypothyroidism and goitriferous effect, though not of such severity as untreated group. Overall, the follicles in shape and size become more "typical", but many of them had hypertrophy and hyperplasia of follicular thyrocytes, cells dystrophy (Fig. 5, a, b).

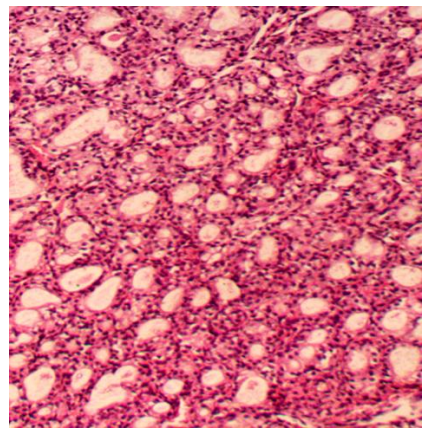

$a$

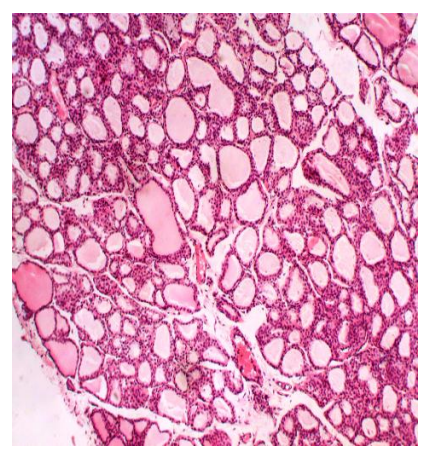

$c$

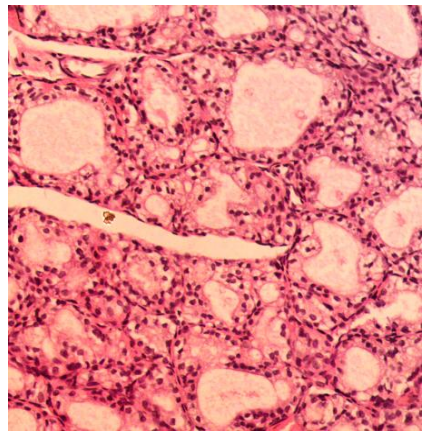

b

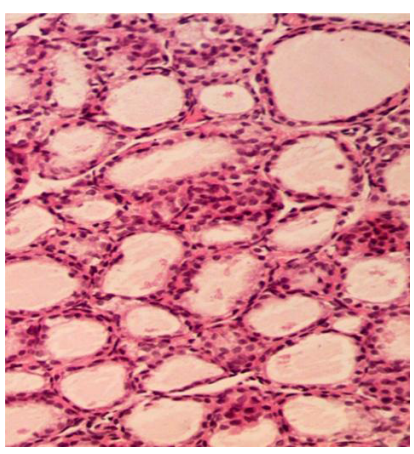

$d$

Fig. 5. Thyroid gland of rats treated with aqueous extract from duckweed Lemna minor, $a, b-$ visible signs of hypothyroidism and goitriferous effect $(\times 100, \times 200)$; $c, d$-normal structure $(\times 100, \times 250)$. Hematoxylin-eosin 
Microscopic picture of the thyroid gland in animals treated with drug Iodomarin 200 in the course of sodium perchlorate introduction showed an increase of its functional activity in $67 \%$ of rats compared to untreated group. Most follicles ranged in size within "acceptable" standards, shapewas typical. Colloid was not determined in all follicles and had the different view. Follicular thyrocytes in the wall of the follicles had mostly high cubic shape, arranged in a row. Dystrophy, expressive hypertrophy and hyperplasia of the thyroid epithelium were observed in a relatively small number of follicles. Hyperplastic sings of extra follicular epithelium reduced and were focal (Fig. 6, $\boldsymbol{a}, \boldsymbol{b})$.

In $33 \%$ of the rats, microscopic picture of the structure of thyroid gland visually unchanged compared to the hypothyroid group: the same diffuse monomorphic follicles, absence of colloid; dystrophy, hypertrophy and hyperplasia of thyrocytes, focal hyperemia of perifollicular capillary net (Fig. 7, $\boldsymbol{a}, \boldsymbol{b})$.

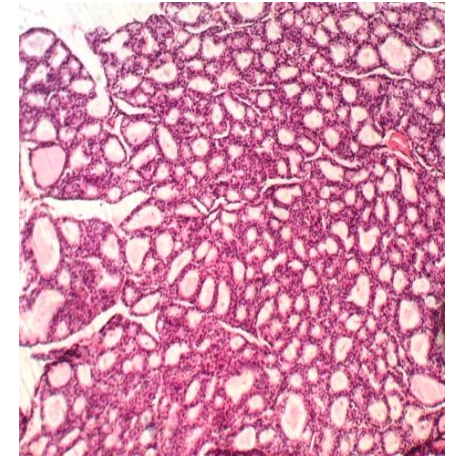

$a$

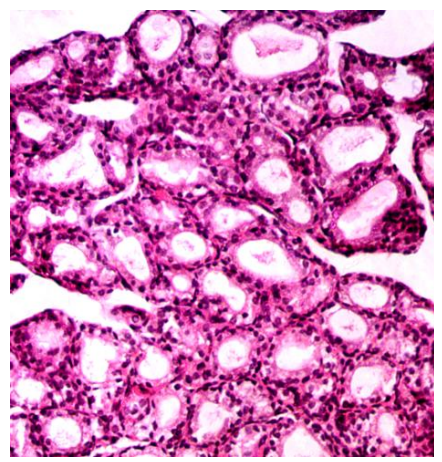

$b$

Fig. 6. Thyroid gland of rats treated with Iodomarin 200,

$a$-gland structure is close to normal $(\times 100) ; b$ - follicular thyrocytes of most follicles have a typicalview, colloid density $(\times 200)$. Hematoxylin-eosin

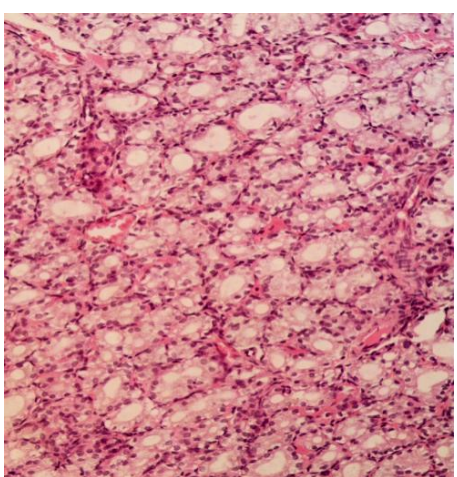

$a$

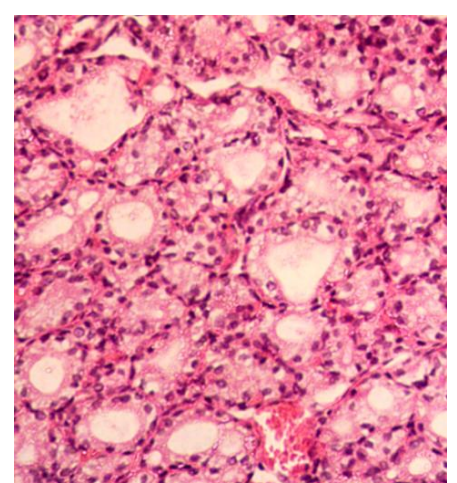

$b$

Fig. 7. The thyroid gland of rats treated with Iodomarin 200; $a$-diffuse monomorphic follicles $(\times 100) ; b$-dystrophy, hypertrophy and hyperplasia of follicular thyrocytes, the absence of colloid in the lumen of the follicles $(\times 200)$. Hematoxylin-eosin

Such differences in the structural organization of the thyroid gland affected the averages parameters that characterized its functional state inside the group. The outer diameter of the follicles reduced compared to control by only $6.79 \%(\mathrm{P}>0.05)$, the number of follicular thyrocytes in the wall of the follicles significantly decreased by $14.24 \%(\mathrm{P}<0.05)$, the height of the cells also significantly reduced by $32.28 \%(\mathrm{P}<0.05)$ (Table $\mathbf{1})$.

\section{Conclusions}

In conclusion, the data obtained in this study suggest that sodium perchlorate markedly inhibits the functional activity of the thyroid glands in rats, causing morphological features inherent in the iodine 
deficiency state. Treatment of rats in experimental hypothyroidism with aqueous extract from duckweed Lemna minor frond showed corrective effects on the thyroid gland structure, whichresulted in the decrease of the external diameter of the follicle, height and number of the wall of the follicle. Therefore, it may be useful for preventing or delaying the development of hypothyroidism and its complications.

\section{Acknowledgments}

The authors wish to thank the staff of the Central Scientific Research Laboratory of the National University of Pharmacy for the care of the experimental animals throughout the period of this research work.

\section{References}

[1] Fadeev, V. V. (2012). Problems of substitution treatment of hypothyroidism: present and prospects. Clinical and Experimental Thyroidology, 8 (3), 12-17.

[2] Mancini, A., Raimondo, S., Di, C., Persano, M., Pontecorvi, A. (2013). Non-Thyroidal Illness: Physiopathology and Clinical Implications. Current Topics in Hypothyroidism with Focus on Development. doi: $10.5772 / 55644$

[3] Ozpinar, A., Golub, M. S., Poppenga, R. H., Blount, B. C., Gillespie, J. R. (2011). Thyroid status of female rhesus monkeys and preliminary information on impact of perchlorate administration. Laboratory Animals, 45 (3), 209-214. doi:10.1258/1a.2011.010047

[4] Pankiv, V. I. (2012). General Thyroidology. Inter Journal of Endocrinology, 2 (42). Available at: http://www.mif-ua.com/archive/article/27390

[5] Volkov, V. P. (2014). A new approach to the evaluation of the morphofunctional state of the endocrine glands.Universum, 9 (10). Available at:http://7universum.com/en/med/archive/item/1589

[6] Bajaj, J. K., Salwan, P., Salwan, S. (2016). Various possible toxicants involved in thyroid dysfunction: A Review. Journal of Clinical and Diagnostic Research, 10 (01), FE01-FE03.doi: 10.7860/jcdr/2016/15195.7092

[7] Kravchenko, V. I., Postol, S. V. (2011). Dynamics of the incidence of thyroid pathology in Ukraine. International Journal of Endocrinology, 3 (35), 26-31.

[8] Lebedynets, N. V., Parubocha, O. M. (2012). Modern aspects of the dynamics of endocrine pathology of the child population. Environment Health, 3, 21-25.

[9] Filatova, S. V. (2010). Thyroid disease treatment traditional and non-traditional ways.Rypol Classic, 256.

[10] Javed, Z.,Sathyapalan, T. (2015). Levothyroxine treatment of mild subclinical hypothyroidism: a review of potential risks and benefits. Therapeutic Advances in Endocrinology and Metabolism, 7 (1), $12-23$. doi: $10.1177 / 2042018815616543$

[11] Mangge, H. (2014). Antioxidants, inflammation and cardiovascular disease.World Journal of Cardiology, 6(6), 462.doi: 10.4330/wjc.v6.i6.462

[12] Vladimirova, I. M. (2014). The standardization of approaches to targeted search of herbal medicines for the treatment of thyroid disease.Kharkiv, 440.

[13] Vladimirova, I. M., Georgiyants, V. A. (2010). Analytical review of current thyroid-stimulating agents.Pharmaceutical journal, 4, 90-93.

[14] Nikiphorov, L. A., Belousov, M. V., Fursa, N. S. (2011). Study of amino acid composition of duckweed (Lemna minor L.).BulletenSibirskoyMedicini, 5, 74-77.

[15] Vladimirova, I. M., Georgiyants, V. A. (2013). Biological active substances of Lemna minor S. F. gray. Pharmaceutical Chemistry Journal, 47(11), 29-31.

[16] Mohamed, D. A. (2015). Histological Study of Thyroid Gland after Experimental Exposure to Low Frequency Electromagnetic Fields in Adult Male Albino Rat and Possible Protective Role of Vitamin E. Journal of Cytology \& Histology, 06 (06). doi: 10.4172/2157-7099.1000374

[17] Yu, K. (2002). The Pharmacokinetics of Perchlorate and Its Effect on the Hypothalamus-PituitaryThyroid Axis in the Male Rat. Toxicology and Applied Pharmacology, 182(2), 148-159. doi:10.1006/taap.2002.9432

[18] Merkulov, G. A. (1969). Course of pathologic-histological technology. Moscow: Medicine, 424.

[19] Khalaphyan, A. A.(2007). STATISTICA 6: Statistical analysis of data. Moscow:Binom-Press, 512.

[20] Lapach, S. N., Chubenko, A. V., Babich, P. N. (2001). Statistical methods in biomedical research using Excel.Kyiv: Morion, 320. 